\title{
A water-stable fcu-MOF material with exposed amino groups for the multi-functional separation of small molecules
}

\author{
Ke Jiang, Ling Zhang, Tifeng Xia, Yu Yang, Bin Li, Yuanjing Cui ${ }^{*}$ and Guodong Qian*
}

\begin{abstract}
The energy-efficient purification of methane from $\mathrm{C}_{2}$-hydrocarbons is of great significance for the upgrading of natural gas. So does the capture of carbon dioxide for remission of greenhouse effect. It is well established that some functional sites, such as open metals sites, Lewis basic nitrogen sites and fluorine groups, have shown significantly enhanced affinity toward more polarizable molecules. Thus, a water-stable $\mathrm{Eu}^{3+}$-based fcu-metal-organic framework (MOF) (compound 1) with amino functional groups has been successfully constructed through a reticular chemistry approach. As a result, the activated compound 1 exhibits moderately high uptakes of $\mathrm{C}_{2}$-hydrocarbons, but a less obvious adsorption of $\mathrm{CH}_{4}$ at the same conditions. Among them, the adsorption capacity of $\mathrm{C}_{2} \mathrm{H}_{2}$ is up to $143.6 \mathrm{~cm}^{3} \mathrm{~cm}^{-3}$ and a relatively high selectivity of $\mathrm{C}_{2} \mathrm{H}_{2} / \mathrm{CH}_{4}(107.7)$ is obtained at near room temperature. Moreover, compound 1 is also validated as an exceptional adsorbent for $\mathrm{CO}_{2}$ capture, with the fairly high capacity of $\mathrm{CO}_{2}\left(92.6 \mathrm{~cm}^{3} \mathrm{~cm}^{-3}\right)$ and $\mathrm{CO}_{2} / \mathrm{N}_{2}$ selectivity (151.7) at ambient conditions. The excellent performance of compound 1 is mainly driven by the exposed amino functional groups within the contracted pores. Such effect thus leads to the achievement of dual-functional platform for methane purification and carbon dioxide capture. Furthermore, compound 1 features a satisfactory water stability, which is confirmed by the powder X-ray diffraction (PXRD) analysis and the retest of porosity after being soaked in water.
\end{abstract}

Keywords: porous material, metal-organic frameworks, small molecule gas, functional groups, gas selectivity

\section{INTRODUCTION}

Methane $\left(\mathrm{CH}_{4}\right)$ is the main valuable component of natural gas and perceptibly considered as an alternative to conventional fossil fuels due to its abundance and en- vironment-friendly features [1-4]. Hence, to obtain highpurity methane from $\mathrm{C}_{2}$-hydrocarbon impurities is of great importance for the upgrading of natural gas. Nevertheless, this purification has been mainly accomplished by energy-intensive cryogenic fractionation at present. Besides, the excessive release of $\mathrm{CO}_{2}$ from the typical power plants results in the worrisome greenhouse effect [5-7]. However, the conventional alkylamine-containing liquids applied for $\mathrm{CO}_{2}$ capture are faced with high regeneration cost. Thus, the construction of efficient gas capture and purification system is necessary, especially in energy-efficient ways.

Adsorptive separation based on porous materials is considered as a non-thermal separation. Thus, it is regarded as a suitable alternative to save the tremendous energy of distillation-based separation. Metal-organic frameworks (MOFs) [8-23], a class of promising porous materials, offer promise for gas storage and separation due to their highly versatile nature in pore structure and functionalization [24-37]. Some accomplished pore tuning strategies were used to directly increase the pore sizes within MOFs aiming at gas storage at high pressure. Nevertheless, the contracted pore apertures, relative to the enlarged pores, possibly show better performance at gas separation due in part to their potential size sieve effect. Moreover, many studies have been realized that MOFs with functional sites, including open metal sites (OMS) [38], Lewis basic nitrogen sites [39] and fluorine groups [40], show enhanced affinity toward more polarizable molecules via thermodynamic selectivity. In fact, many copper- and zinc-based MOFs have indeed shown the benchmark performance at gas separation and purification. However, most of them are hardly deployed under real-world conditions since they undergo hydro-

State Key Laboratory of Silicon Materials, Cyrus Tang Center for Sensor Materials and Applications, School of Materials Science and Engineering, Zhejiang University, Hangzhou 310027, China

* Corresponding authors (emails: cuiyj@zju.edu.cn (Cui Y); gdqian@zju.edu.cn (Qian G)) 
lysis in the presence of moisture [41,42].

Herein, we opted to use a 2-connected bridging ligand equipped with amino group, to successfully construct a rare-earth (RE) fcu-MOF material (compound 1) [43,44]. As a result, the highly-connected fcu topology guarantees the rigidity of framework to a great extent. It is depressing that few RE based MOFs were explored for gas separation and purification, plausibly due to that most of MOFs lack OMS and/or robustly available porosity. Thus, we incorporated amino functional groups on the pore walls of this material, which would selectively enhance the affinity toward polarizable molecules (i.e. $\mathrm{C}_{2}$-hydrocarbon and $\mathrm{CO}_{2}$ ) (Table 1), thus further improve the gas selectivity. As a result, this activated material exhibits moderately high uptakes of $\mathrm{C}_{2}$-hydrocarbon $\left(86.6-143.6 \mathrm{~cm}^{3} \mathrm{~cm}^{-3}\right)$, but a less obvious adsorption for $\mathrm{CH}_{4}\left(22.6 \mathrm{~cm}^{3} \mathrm{~cm}^{-3}\right)$ at near room temperature. Thus, the relatively high $\mathrm{C}_{2} / \mathrm{CH}_{4}$ selectivities (35.9-138.8) have been obtained which are even comparable to other top-performing materials reported so far. Moreover, most MOF adsorbents show moderate uptake of $\mathrm{CO}_{2}$ (generally below $2.0 \mathrm{mmol} \mathrm{g}^{-1}$ ) and the selectivities of $\mathrm{CO}_{2} / \mathrm{N}_{2}$ in these MOFs are generally below 100 . Conversely, compound 1 features a potential block-off of $\mathrm{N}_{2}$ gas, thus resulting in a very high selectivity of $\mathrm{CO}_{2} / \mathrm{N}_{2}$ separation up to 151.7 at ambient conditions. Thus, compound $\mathbf{1}$ is also validated as an exceptional adsorbent for $\mathrm{CO}_{2}$ capture among the reported MOFs, with the moderately high capacity of $\mathrm{CO}_{2}$ $\left(92.6 \mathrm{~cm}^{3} \mathrm{~cm}^{-3}\right)$ and very high $\mathrm{CO}_{2} / \mathrm{N}_{2}$ selectivity (151.7). Herein, this resultant fine-tuned MOF material permits the achievement of a dual-functional platform for effective $\mathrm{CH}_{4}$ purification and carbon dioxide capture. Such excellent performance of this MOF adsorbent is mostly driven by the incorporation of amino functional groups within the restricted apertures. It is noteworthy that this material features an exceptional chemical stability, further confirmed by powder X-ray diffraction (PXRD) analysis and the retest of porosity after being soaked in deionized water for two days.

\section{EXPERIMENTAL SECTION}

\section{Materials and methods}

All reagents and solvents were commercially available and used without further purification. Infrared spectrum (IR) was performed on a Thermo Fisher Nicolet iS10 spectrometer using $\mathrm{KBr}$ pallets. Thermogravimetric analyses (TGA) were carried out on a Netzsch TG209F3 with a heating rate of $10^{\circ} \mathrm{C} \mathrm{min}^{-1}$ in $\mathrm{N}_{2}$ atmosphere. PXRD patterns were collected in the $2 \theta=5^{\circ}-60^{\circ}$ range on an
Table 1 Important physical parameters of the selected gas adsorbates

\begin{tabular}{ccc}
\hline Adsorbate & Kinetic diameter $(\AA)$ & Polarizability $\left(10^{25} \mathrm{~cm}^{-3}\right)$ \\
\hline $\mathrm{N}_{2}$ & $3.64-3.80$ & 17.403 \\
$\mathrm{CO}_{2}$ & 3.3 & 29.11 \\
$\mathrm{CH}_{4}$ & 3.758 & 25.93 \\
$\mathrm{C}_{2} \mathrm{H}_{2}$ & 3.3 & $33.3-39.3$ \\
$\mathrm{C}_{2} \mathrm{H}_{4}$ & 4.163 & 42.52 \\
$\mathrm{C}_{2} \mathrm{H}_{6}$ & 4.443 & $44.3-44.7$ \\
\hline
\end{tabular}

X'Pert PRO diffractometer with $\mathrm{Cu} \mathrm{Ka}(\lambda=1.542 \AA)$ radiation at room temperature. The morphology was investigated using a field-emission scanning electron microscopy (FE-SEM, Hitachi S4800). Crystallographic measurements were taken on an Oxford Xcalibur Gemini Ultra diffractometer equipped with an Atlas detector using graphite-monochromatic Mo Ka radiation $(\lambda=$ $0.71073 \AA$ ) at $293 \mathrm{~K}$.

\section{Synthesis of Eu ${ }^{3+}$-based fcu-MOF (compound 1)}

A mixture of the organic linker 2-aminoterephthalic acid $\left(\mathrm{H}_{2} \mathrm{BDC}-\mathrm{NH}_{2}, 131.3 \mathrm{mg}, 0.725 \mathrm{mmol}\right), \mathrm{Eu}\left(\mathrm{NO}_{3}\right)_{3} \cdot 6 \mathrm{H}_{2} \mathrm{O}$ (323.4 $\mathrm{mg}, \quad 0.725 \mathrm{mmol}$ ) and 2-fluorobenzoic acid (2-FBA, $812.6 \mathrm{mg}, 5.8 \mathrm{mmol}$ ) was dissolved into $41.5 \mathrm{~mL}$ mixed solvent ( $N, N$-dimethyllformamide $(\mathrm{DMF}) / \mathrm{H}_{2} \mathrm{O} /$ $\mathrm{HNO}_{3}, \quad 36.5 \mathrm{~mL} / 3 \mathrm{~mL} / 2 \mathrm{~mL}, \mathrm{HNO}_{3} \quad\left(3.5 \mathrm{~mol} \mathrm{~L}^{-1}\right.$ in $\mathrm{DMF})$ ) in a $100-\mathrm{mL}$ Teflon cup. The Teflon cup was capped and heated in an oven at $110^{\circ} \mathrm{C}$ for $60 \mathrm{~h}$. The transparent polyhedral crystals were obtained by filtration and washed with DMF several times to afford $\mathrm{Eu}^{3+}$-based fcu-MOF.

\section{Gas sorption measurements}

The gas sorption isotherms were measured by the Micromeritics ASAP 2020 surface area analyzer. In order to remove all the guest solvents from compound $\mathbf{1}$, the fresh sample was guest-exchanged with dry acetone at least 10 times, filtered and degassed at $298 \mathrm{~K}$ for 1 day and $373 \mathrm{~K}$ for $10 \mathrm{~h}$ successively under high vacuum until the outgas rate was $5 \mu \mathrm{mHg} \mathrm{min}{ }^{-1}$ to yield the activated material for further gas sorption studies. The sorption measurement was maintained at $77 \mathrm{~K}$ with liquid nitrogen. An icewater bath and water bath were used for adsorption isotherms at 273 and $298 \mathrm{~K}$, respectively.

\section{RESULTS AND DISCUSSION}

Reactions of $\mathrm{Eu}\left(\mathrm{NO}_{3}\right)_{3} \cdot 6 \mathrm{H}_{2} \mathrm{O}$ with the organic linker, $\mathrm{H}_{2} \mathrm{BDC}-\mathrm{NH}_{2}$ (Fig. S1), in the solvothermal condition successfully yielded transparent polyhedral crystals Eu- 
BDC- $\mathrm{NH}_{2}$ (compound 1). The morphology of the synthesized material was characterized comprehensively by optical microscopy and FE-SEM. As illustrated in Fig. 1, it displays a homogeneous polyhedral morphology with a particle size of around $50 \mu \mathrm{m}$. The phase purity of the bulk material was further confirmed by PXRD analyses (Fig. S2).

The crystal structure reveals that compound 1 crystallizes in $F m 3 m$ space group as depicted in Fig. 2. The adjacent $\mathrm{Eu}^{3+}$ ions are bridged with deprotonated BDC$\mathrm{NH}_{2}{ }^{2-}$ and $\mu_{3}-\mathrm{OH}$ to give 12 -connected MBBs $\left[\mathrm{Eu}_{6}\left(\mu_{3}-\right.\right.$ $\left.\mathrm{OH})_{8}\left(\mathrm{O}_{2} \mathrm{C}-\right)_{12}\right]$ (Fig. 2a). Accordingly, the carbon atoms of the coordinated carboxylates act as points of extension, which further coordinate the carboxylate ligands and MBBs to form a 3D framework (Fig. 2b). The resultant compound 1 features a rigid fcu topology that is isostructural to the net in the NDC-fcu-MOF [43]. The structure in compound $\mathbf{1}$ encloses two distinct cages of octahedral and tetrahedral cages. Correspondingly, the average sizes are estimated to be 4.0 and $7.8 \AA$ for octahedral and tetrahedral cages, respectively. Most importantly, extensive amino groups expose on the pore wall within the framework, rendering it bright potential for small molecule separation and purification.

We further characterized its permanent porosity. After the sufficient acetone-exchange, the crystal sample was

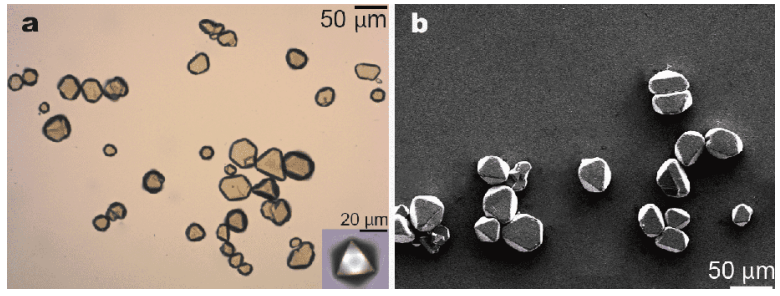

Figure 1 The optical microscopy image (a) and FE-SEM image of compound 1 (b), displaying the homogeneous polyhedral morphology with a particle size of around $50 \mu \mathrm{m}$.

evacuated at $298 \mathrm{~K}$ for 1 day and $373 \mathrm{~K}$ for $10 \mathrm{~h}$ successively to yield the activated material. It is noteworthy that the structure of compound $\mathbf{1}$ after activation still holds the pristine topology, as determined by PXRD analysis (Fig. S2). Permanent porosity studies of activated 1 were performed by nitrogen sorption studies at $77 \mathrm{~K}$. The corresponding isotherms (Fig. 3) show a classical Type-I sorption behavior with a saturation uptake of $9.13 \mathrm{mmol} \mathrm{g}^{-1}$ and a pore volume of $0.32 \mathrm{~cm}^{3} \mathrm{~g}^{-1}$. Thus, the corresponding Brunauer-Emmett-Teller (BET) surface area was estimated to be $605.8 \mathrm{~m}^{2} \mathrm{~g}^{-1}$. Moreover, the distribution of pore aperture was dominantly focused on 4.1 and $7.3 \AA$, basically consistent with the theoretical results from the crystal structure. Particularly, an exceptional water stability of compound $\mathbf{1}$ was determined via

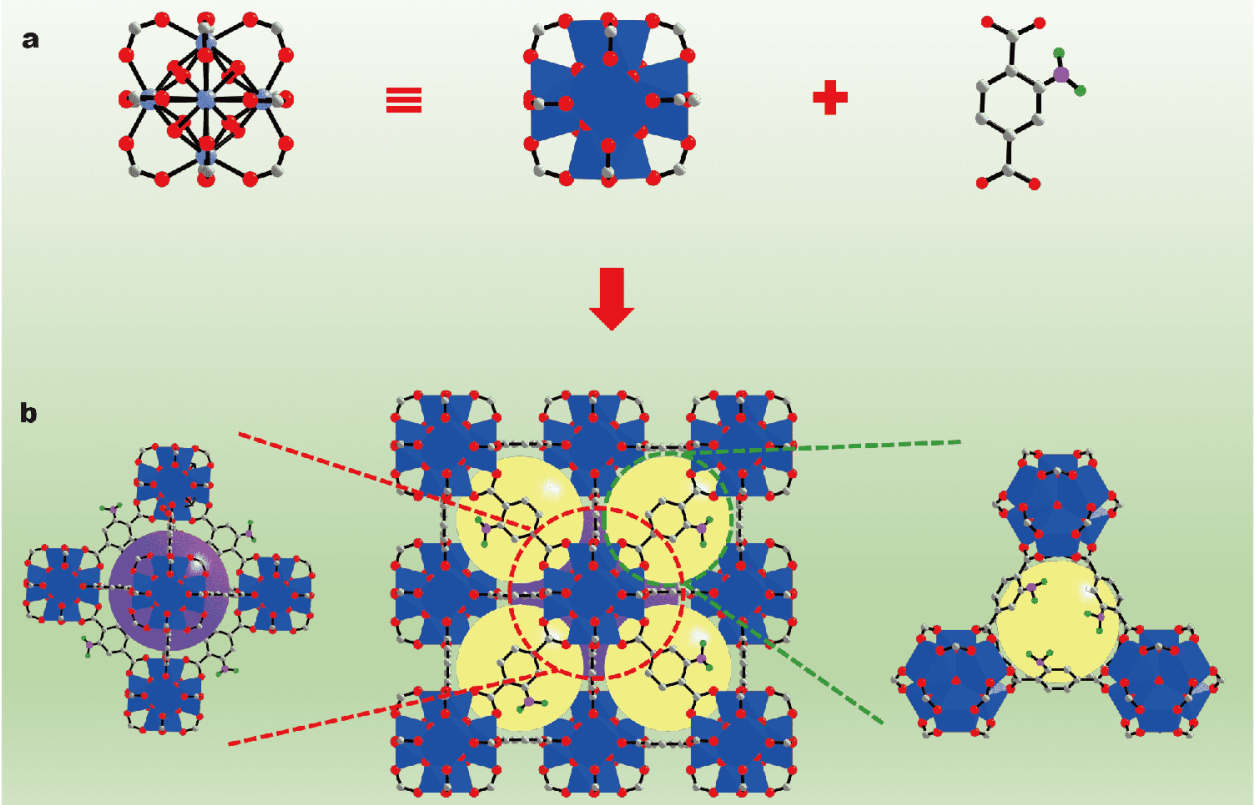

Figure $2 \mathrm{X}$-ray single crystal structure of compound 1 indicating that, (a) the 12-connected $\mathrm{Eu}_{6} \mathrm{O}_{4}(\mathrm{OH})_{4}\left(\mathrm{CO}_{2}\right)_{12}$ molecular building block (MBB) and the 2-connected linker (2-aminoterephthalic acid); (b) the bigger octahedral cage constructed from $6 \mathrm{MBBs}$ and 12 ligands with a diameter of around $7.8 \AA$, while the smaller tetrahedral cage constructed from 4 MBBs and 6 ligands with a diameter of around $4.0 \AA$, and the 3D framework is viewed from $a, b$ or $c$ axes (C, white; $\mathrm{O}$, red; Eu, cambridge blue; $\mathrm{N}$, purple; $\mathrm{H}$, green). 


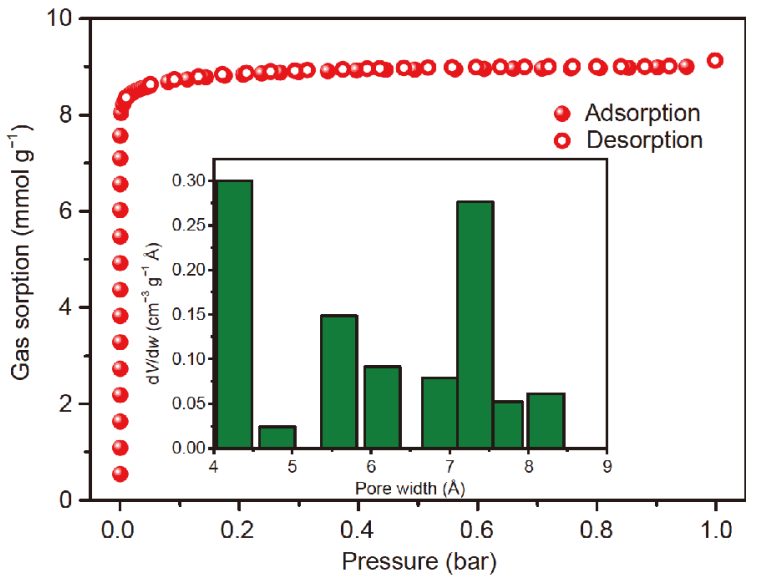

Figure $3 \mathrm{~N}_{2}$ sorption isotherms and pore size distribution of compound 1 at $77 \mathrm{~K}$. Closed symbols, adsorption; open symbols, desorption.

the PXRD analysis and the retest of porosity after soaking it in deionized water for 2 days (Figs S2 and S3). In other words, compound $\mathbf{1}$ is stable enough to maintain its structural integrity from water/moisture attack under real-world conditions. Further, the thermogravimetric analysis of compound $\mathbf{1}$ indicates that its framework could be thermally stable up to $350^{\circ} \mathrm{C}$, featuring its highly thermal stability (Fig. S4).

Inspired by the extensive amino groups within the contracted pores and water stability of compound $\mathbf{1}$, we further investigated it for gas adsorption and separation at low pressure. Thus, the adsorption tests of $\mathrm{C}_{2}$ hydrocarbons (i.e., $\mathrm{C}_{2} \mathrm{H}_{2}, \mathrm{C}_{2} \mathrm{H}_{4}$, and $\mathrm{C}_{2} \mathrm{H}_{6}$ ) and $\mathrm{CH}_{4}$ were carried out at 298 and $273 \mathrm{~K}$, respectively (Fig. 4). The $\mathrm{C}_{2}$ hydrocarbon adsorption isothermals especially for $\mathrm{C}_{2} \mathrm{H}_{2}$ isothermal, are much steeper than the corresponding isothermal of $\mathrm{CH}_{4}$, indicating relatively stronger affinity of the framework toward $\mathrm{C}_{2}$ over $\mathrm{CH}_{4}$. Moreover, the gas uptake capacities at atmospheric pressure (Table 2), finally follow the sequence of $\mathrm{C}_{2} \mathrm{H}_{2}>\mathrm{C}_{2} \mathrm{H}_{4}>\mathrm{C}_{2} \mathrm{H}_{6}>\mathrm{CH}_{4}$. Thus, it is a desired feature for compound $\mathbf{l}$ on separating $\mathrm{C}_{2}$ from $\mathrm{CH}_{4}$. Among them, the adsorption capacity of $\mathrm{C}_{2} \mathrm{H}_{2}$ is highest up to $113.1 \mathrm{~cm}^{3} \mathrm{~cm}^{-3}\left(75.4 \mathrm{~cm}^{3} \mathrm{~g}^{-1}\right)$, significantly higher than that of $\mathrm{CH}_{4}\left(17.9 \mathrm{~cm}^{3} \mathrm{~cm}^{-3}\right)$ at ambient conditions (Fig. 4b). The $\mathrm{C}_{2} \mathrm{H}_{2}$ uptake of compound $\mathbf{1}$ is lower than some copper-based MOF materials with ultra-high porosity and open metal sites, such as
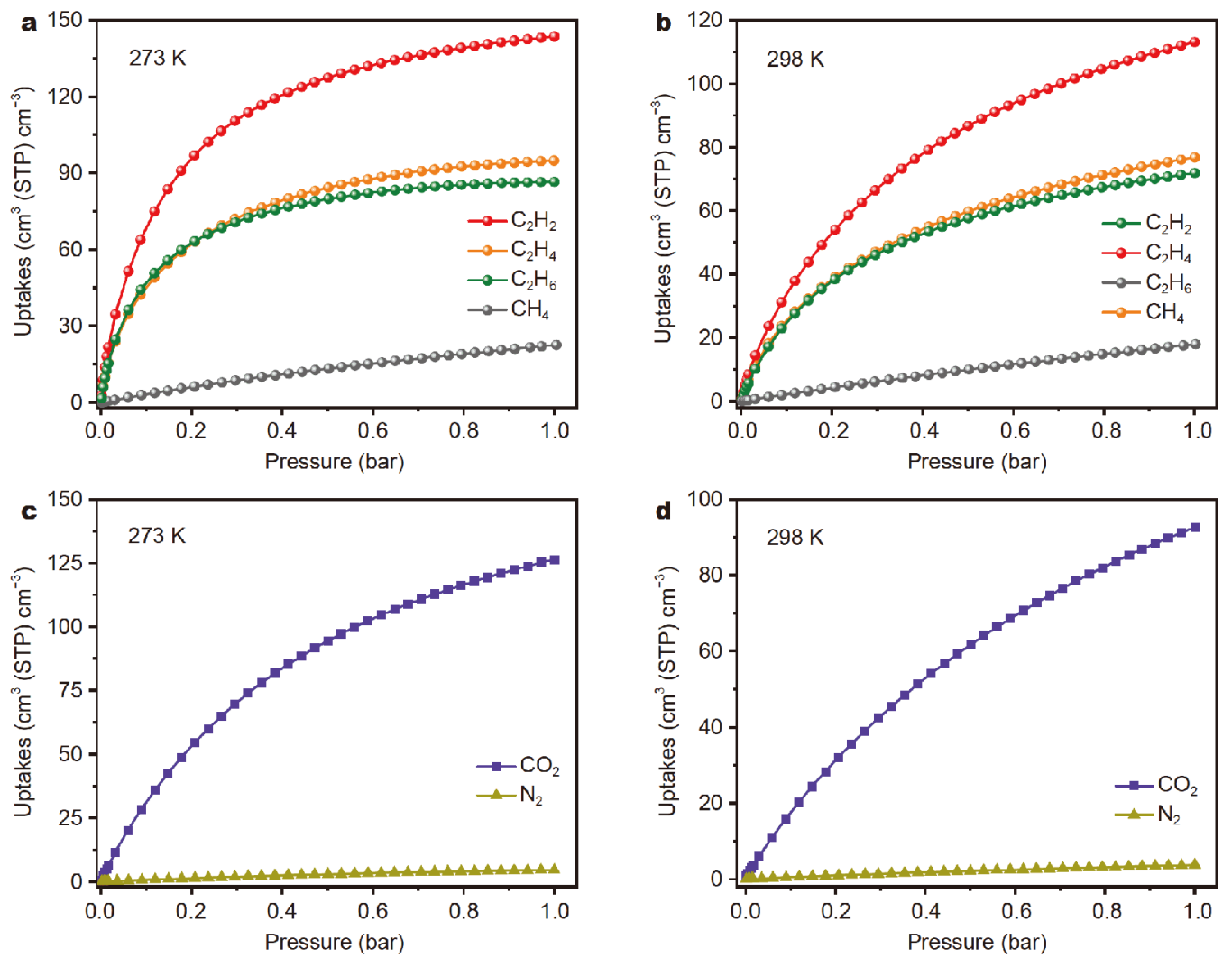

Figure 4 Single-component adsorption isotherms of compound 1 for $\mathrm{C}_{2}$-hydrocarbons and $\mathrm{CH}_{4}$ at 273 (a) and $298 \mathrm{~K}$ (b); single-component adsorption isotherms of compound $\mathbf{1}$ for $\mathrm{CO}_{2}$ and $\mathrm{N}_{2}$ at 273 (c) and $298 \mathrm{~K}$ (d). 
Table 2 The gas sorption, selectivity and $Q_{\text {st }}$ of compound 1

\begin{tabular}{|c|c|c|c|c|c|c|}
\hline Adsorbate & $\mathrm{C}_{2} \mathrm{H}_{2}$ & $\mathrm{C}_{2} \mathrm{H}_{4}$ & $\mathrm{C}_{2} \mathrm{H}_{6}$ & $\mathrm{CH}_{4}$ & $\mathrm{CO}_{2}$ & $\mathrm{~N}_{2}$ \\
\hline Uptake capacity at $273 \mathrm{~K}$ and $1.0 \mathrm{bar}\left(\mathrm{cm}^{3} \mathrm{~cm}^{-3}\right)$ & 143.6 & 94.9 & 86.6 & 22.6 & 126.4 & 4.5 \\
\hline Uptake capacity at $298 \mathrm{~K}$ and $1.0 \mathrm{bar}\left(\mathrm{cm}^{3} \mathrm{~cm}^{-3}\right)$ & 113.1 & 76.8 & 71.9 & 17.9 & 92.6 & 3.7 \\
\hline $\mathrm{S}_{\mathrm{i} / \mathrm{CH}_{4}}$ or $\mathrm{S}_{\mathrm{i} / \mathrm{N}_{2}}$ at $273 \mathrm{~K}$ & 107.7 & 47.3 & 39.7 & / & 474.1 & / \\
\hline $\mathrm{S}_{\mathrm{i} / \mathrm{CH}_{4}}$ or $\mathrm{S}_{\mathrm{i} / \mathrm{N}_{2}}$ at $298 \mathrm{~K}$ & 33.4 & 30.5 & 22.3 & I & 151.7 & I \\
\hline$Q_{\text {st }}\left(\mathrm{kJ} \mathrm{mmol}^{-1}\right)$ & 34.5 & 32.8 & 34.0 & 16.1 & 18.3 & 13.0 \\
\hline
\end{tabular}

ZJNU-71 (200.4 $\left.\mathrm{cm}^{3} \mathrm{~g}^{-1}\right)$ [45], ZJU-195 $\left(214 \mathrm{~cm}^{3} \mathrm{~g}^{-1}\right)$ [46] and FJI-H8 $\left(224 \mathrm{~cm}^{3} \mathrm{~g}^{-1}\right)$ [47]. However, it is significantly higher than other promising materials, such as M'MOF-20a $\left(21 \mathrm{~cm}^{3} \mathrm{~g}^{-1}\right)$ [48], UTSA-72a $\left(27.8 \mathrm{~cm}^{3} \mathrm{~g}^{-1}\right)$ [49], UTSA-15a $\left(34 \mathrm{~cm}^{3} \mathrm{~g}^{-1}\right)$ [50] and ZJU-30 $\left(52.6 \mathrm{~cm}^{3} \mathrm{~g}^{-1}\right)$ [51]. Especially, the adsorption capacity of $\mathrm{C}_{2} \mathrm{H}_{2}$ can be further improved to $143.6 \mathrm{~cm}^{3} \mathrm{~cm}^{-3}$ when the temperature reduces to $273 \mathrm{~K}$ (Fig. 4a). Such distinctive adsorption performance of compound $\mathbf{l}$ is mainly attributed to the enhanced affinity between the extensive amino groups on the pore wall and the $\mathrm{C}_{2}$ hydrocarbons.

In light of the aforementioned results, we envisioned that such feature of compound $\mathbf{1}$ should be available for other separation. Thus, we further explored the separation of other small molecules, including the capture of
$\mathrm{CO}_{2}$ over $\mathrm{N}_{2}$. As expected, almost no uptake for $\mathrm{N}_{2}$ gas was observed at both 273 and $298 \mathrm{~K}$. Conversely, it selectively captured $\mathrm{CO}_{2}$ molecule up to $126.4 \mathrm{~cm}^{3} \mathrm{~cm}^{-3}$ and $92.6 \mathrm{~cm}^{3} \mathrm{~cm}^{-3}$ at 273 and $298 \mathrm{~K}$, respectively (Fig. $4 \mathrm{c}, \mathrm{d}$ ). Such exceptional features of compound 1 lead to the achievement of dual-functional platform in methane purification and $\mathrm{CO}_{2}$ capture.

We further utilized the recognized ideal adsorbed solution theory (IAST) to calculate the equilibrium selectivity for $\mathrm{C}_{2} / \mathrm{CH}_{4}(50 / 50, v / v)$ and $\mathrm{CO}_{2} / \mathrm{N}_{2}(20 / 80, v / v)$ mixtures. The results of IAST calculations for $\mathrm{C}_{2} / \mathrm{CH}_{4}$ and $\mathrm{CO}_{2} / \mathrm{N}_{2}$ at 273 and $298 \mathrm{~K}$ are expressed in Fig. 5 and Table 2. Compound $\mathbf{1}$ exhibits a relatively high selectivity for $\mathrm{C}_{2} / \mathrm{CH}_{4}$ both at 273 and $298 \mathrm{~K}$ (Fig. 5a, b). Especially, the selectivity value of $\mathrm{C}_{2} \mathrm{H}_{2}$ over $\mathrm{CH}_{4}$ is high up to 33.4 at
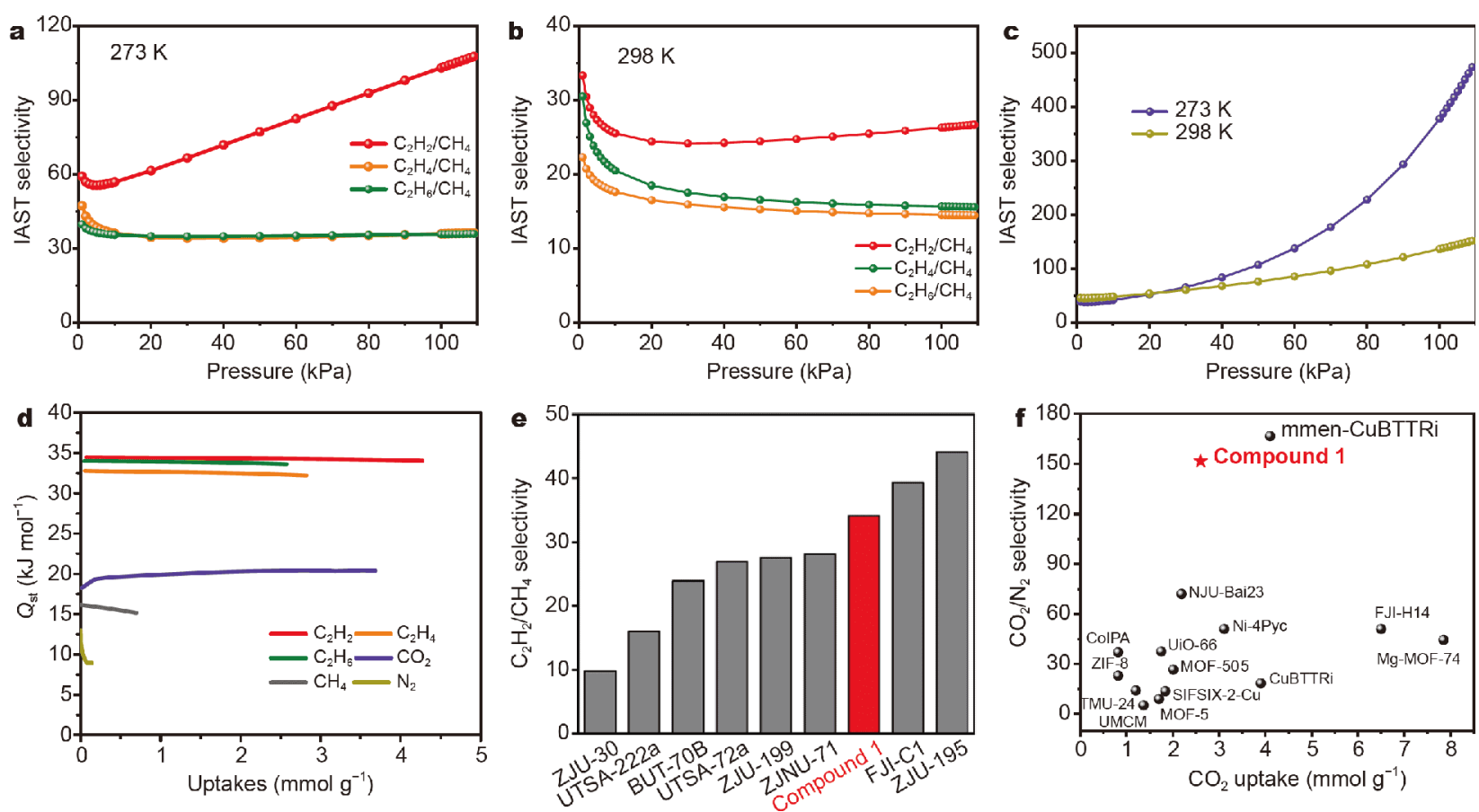

Figure 5 IAST calculations of compound 1 for $\mathrm{C}_{2} / \mathrm{CH}_{4}$ selectivity at 273 (a) and $298 \mathrm{~K}$ (b); IAST calculations of compound $\mathbf{1}$ for $\mathrm{CO}_{2} / \mathrm{N}_{2}$ selectivity (c); the isosteric heats of gases in compound $\mathbf{1}$ (d); comparison of reported MOF materials for $\mathrm{C}_{2} \mathrm{H}_{2} / \mathrm{CH}_{4}$ selectivity (e); comparison of reported MOF materials for $\mathrm{CO}_{2}$ uptake and $\mathrm{CO}_{2} / \mathrm{N}_{2}$ selectivity (f). 
ambient conditions, among the promising MOF materials ever reported for $\mathrm{C}_{2}$-hydrocarbons/methane separation (Fig. 5e). The value of $\mathrm{C}_{2} \mathrm{H}_{2} / \mathrm{CH}_{4}$ selectivity for compound 1 is just lower than those of ZJU-195 (43.4) [46] and FJI-C1 (39.3) [52], but higher than other porous materials like ZJU-30 (9.59) [51], UTSA-222a (16) [53] and BUT-70B (23.3) [54]. Moreover, the selectivity of $\mathrm{C}_{2} \mathrm{H}_{2}$ versus $\mathrm{CH}_{4}$ can be further improved to 107.7 when the operation temperature is decreased to $273 \mathrm{~K}$. Apparently, compound $\mathbf{1}$ is a promising adsorbent for the upgrading of fairly.

Moreover, fairly high selectivities of $\mathrm{CO}_{2} / \mathrm{N}_{2}$ have been obtained up to 474.1 and 151.7 for 273 and $298 \mathrm{~K}$, respectively, owing to the almost block-off for $\mathrm{N}_{2}$ adsorption. Thus, we further compared the $\mathrm{CO}_{2}$ uptake and the $\mathrm{CO}_{2} / \mathrm{N}_{2}$ selectivity among the reported MOF materials (Fig. 5f). We can read that most MOF adsorbents show moderate uptake of $\mathrm{CO}_{2}$ (generally below $2.0 \mathrm{mmol} \mathrm{g}^{-1}$ ) [55-59] except few MOFs materials like Mg-MOF-74 [60-62] with ultra-high open metal sites. Furthermore, the selectivity values of $\mathrm{CO}_{2} / \mathrm{N}_{2}$ are generally below 100 for most of MOF materials. Thus, compound 1 is recognized as an exceptional adsorbent for $\mathrm{CO}_{2}$ capture among the reported MOF materials, overall considering the moderately high capacity of $\mathrm{CO}_{2}$ and very high $\mathrm{CO}_{2} /$ $\mathrm{N}_{2}$ selectivity.

Such excellent performance reveals the bright promise of compound $\mathbf{1}$ for small molecule separation and purification. The aforementioned results were further confirmed by the isosteric heat of adsorption $\left(Q_{s t}\right)$ which was calculated via the experimental adsorption data, as illustrated in Fig. 5d. As anticipated, all the $Q_{\text {st }}$ values of $C_{2}$ gases were found to be over $30.0 \mathrm{~kJ} \mathrm{~mol}^{-1}$ while only $16.1 \mathrm{~kJ} \mathrm{~mol}^{-1}$ was observed for $\mathrm{CH}_{4}$. Interestingly, the isosteric heat of $\mathrm{C}_{2}$ adsorption does not decrease as gas loading increases. Thus, it indicates the homogenous binding affinity toward $\mathrm{C}_{2}$ hydrocarbons within the whole range of gas loading. Meanwhile, the isosteric heat value of $\mathrm{CO}_{2}\left(18.3 \mathrm{~kJ} \mathrm{~mol}^{-1}\right)$ is higher than the corresponding value of $\mathrm{N}_{2}\left(12.9 \mathrm{~kJ} \mathrm{~mol}^{-1}\right)$, further confirming its much stronger affinity of framework toward more polarizable molecules.

\section{CONCLUSIONS}

In summary, we herein reported a water-stable $\mathrm{Eu}^{3+}$ based fcu-MOF material (compound 1) with exposed amino groups for multi-functional separation of small molecules. The foregoing results of compound 1 permit the achievement of dual-functional platform for methane purification and $\mathrm{CO}_{2}$ capture. The adsorbent affords not only the effective separation of $\mathrm{C}_{2}$ hydrocarbon from $\mathrm{CH}_{4}$, but the excellent capture of $\mathrm{CO}_{2}$ over $\mathrm{N}_{2}$. Among them, the adsorption capacity of $\mathrm{C}_{2} \mathrm{H}_{2}$ is up to $143.6 \mathrm{~cm}^{3} \mathrm{~cm}^{-3}$ and a high selectivity of $\mathrm{C}_{2} \mathrm{H}_{2} / \mathrm{CH}_{4}(107.7)$ are obtained at near room temperature. Moreover, compound $\mathbf{1}$ is also validated as an exceptional adsorbent for $\mathrm{CO}_{2}$ capture, overall considering the fairly high capacity of $\mathrm{CO}_{2}\left(92.6 \mathrm{~cm}^{3} \mathrm{~cm}^{-3}\right)$ and $\mathrm{CO}_{2} / \mathrm{N}_{2}$ selectivity (151.7) at ambient conditions. The excellent water stability further makes this fcu-MOF material as a particularly potential candidate for natural gas upgrading and $\mathrm{CO}_{2}$ capture.

\section{Received 25 February 2019; accepted 2 April 2019;} published online 28 April 2019

1 Choudhary VR, Mayadevi S. Adsorption of methane, ethane, ethylene, and carbon dioxide on high silica pentasil zeolites and zeolite-like materials using gas chromatography pulse technique. Separation Sci Tech, 1993, 28: 2197-2209

2 Cavenati S, Grande CA, Rodrigues AE. Removal of carbon dioxide from natural gas by vacuum pressure swing adsorption. Energy Fuels, 2006, 20: 2648-2659

3 He Y, Zhou W, Qian G, et al. Methane storage in metal-organic frameworks. Chem Soc Rev, 2014, 43: 5657-5678

4 Li JR, Sculley J, Zhou HC. Metal-organic frameworks for separations. Chem Rev, 2012, 112: 869-932

5 Liang CC, Shi ZL, He CT, et al. Engineering of pore geometry for ultrahigh capacity methane storage in mesoporous metal-organic frameworks. J Am Chem Soc, 2017, 139: 13300-13303

6 He M, Wang Y, Gao X, et al. Three ligand-originated MOF isomers: the positional effect of the methyl group on structures and selective $\mathrm{C}_{2} \mathrm{H}_{2} / \mathrm{CH}_{4}$ and $\mathrm{CO}_{2} / \mathrm{CH}_{4}$ adsorption properties. Dalton Trans, 2018, 47: 8983-8991

7 Zhai QG, Bai N, Li SN, et al. Design of pore size and functionality in pillar-layered $\mathrm{Zn}$-triazolate-dicarboxylate frameworks and their high $\mathrm{CO}_{2} / \mathrm{CH}_{4}$ and $\mathrm{C}_{2}$ hydrocarbons/ $/ \mathrm{CH}_{4}$ selectivity. Inorg Chem, 2015, 54: 9862-9868

8 Cui Y, Li B, He H, et al. Metal-organic frameworks as platforms for functional materials. Acc Chem Res, 2016, 49: 483-493

9 Jiang K, Zhang L, Hu Q, et al. Indocyanine green-encapsulated nanoscale metal-organic frameworks for highly effective chemophotothermal combination cancer therapy. Mater Today Nano, 2018, 2: 50-57

10 Huang W, Sun H, Shangguan H, et al. Three-dimensional iron sulfide-carbon interlocked graphene composites for high-performance sodium-ion storage. Nanoscale, 2018, 10: 7851-7859

11 Guo Y, Peng X. Mass transport through metal organic framework membranes. Sci China Mater, 2019, 62: 25-42

12 Gong YN, Ouyang T, He CT, et al. Photoinduced water oxidation by an organic ligand incorporated into the framework of a stable metal-organic framework. Chem Sci, 2016, 7: 1070-1075

13 Teplensky MH, Fantham M, Li P, et al. Temperature treatment of highly porous zirconium-containing metal-organic frameworks extends drug delivery release. J Am Chem Soc, 2017, 139: 75227532

14 Wu H, Shen C, Xia C, et al. Versatile MOF-derived cobalt catalyst for the reductive amination. Sci China Mater, 2017, 60: 1269-1271

15 Jiao L, Jiang HL. Metal-organic-framework-based single-atom 
catalysts for energy applications. Chem, 2019, 5: 786-804

16 Fang Y, Liu W, Teat SJ, et al. A systematic approach to achieving high performance hybrid lighting phosphors with excellent thermal- and photostability. Adv Funct Mater, 2017, 27: 1603444

17 Wang $\mathrm{H}, \mathrm{Xu}$ J, Zhang DS, et al. Crystalline capsules: metal-organic frameworks locked by size-matching ligand bolts. Angew Chem Int Ed, 2015, 54: 5966-5970

18 Zhao D, Kong C, Du H, et al. A molecular-templating strategy to polyamine-incorporated porous organic polymers for unprecedented $\mathrm{CO}_{2}$ capture and separation. Sci China Mater, 2019, 62: 448-454

19 Sasan K, Lin Q, Mao C, et al. Open framework metal chalcogenides as efficient photocatalysts for reduction of $\mathrm{CO}_{2}$ into renewable hydrocarbon fuel. Nanoscale, 2016, 8: 10913-10916

20 Chen CX, Wei ZW, Jiang JJ, et al. Dynamic spacer installation for multirole metal-organic frameworks: a new direction toward multifunctional MOFs achieving ultrahigh methane storage working capacity. J Am Chem Soc, 2017, 139: 6034-6037

21 Liao PQ, Huang NY, Zhang WX, et al. Controlling guest conformation for efficient purification of butadiene. Science, 2017, 356: 1193-1196

22 Aguila B, Sun Q, Wang X, et al. Lower activation energy for catalytic reactions through host-guest cooperation within metalorganic frameworks. Angew Chem, 2018, 130: 10264-10268

23 Yi FY, Chen D, Wu MK, et al. Chemical sensors based on metalorganic frameworks. ChemPlusChem, 2016, 81: 675-690

24 Li B, Wen HM, Yu Y, et al. Nanospace within metal-organic frameworks for gas storage and separation. Mater Today Nano, 2018, 2: 21-49

$25 \mathrm{Hu} \mathrm{TL}$, Wang $\mathrm{H}, \mathrm{Li} \mathrm{B}$, et al. Microporous metal-organic framework with dual functionalities for highly efficient removal of acetylene from ethylene/acetylene mixtures. Nat Commun, 2015, 6: 7328

26 Haldar R, Inukai M, Horike S, et al. ${ }^{113} \mathrm{Cd}$ nuclear magnetic resonance as a probe of structural dynamics in a flexible porous framework showing selective $\mathrm{O}_{2} / \mathrm{N}_{2}$ and $\mathrm{CO}_{2} / \mathrm{N}_{2}$ adsorption. Inorg Chem, 2016, 55: 4166-4172

27 Lin RB, Li L, Wu H, et al. Optimized separation of acetylene from carbon dioxide and ethylene in a microporous material. J Am Chem Soc, 2017, 139: 8022-8028

28 He H, Sun Q, Gao W, et al. A stable metal-organic framework featuring a local buffer environment for carbon dioxide fixation. Angew Chem Int Ed, 2018, 57: 4657-4662

29 Zhang Z, Yao ZZ, Xiang S, et al. Perspective of microporous metalorganic frameworks for $\mathrm{CO}_{2}$ capture and separation. Energy Environ Sci, 2014, 7: 2868-2899

$30 \mathrm{Lu} \mathrm{W}$, Wei Z, Gu ZY, et al. Tuning the structure and function of metal-organic frameworks via linker design. Chem Soc Rev, 2014, 43: 5561-5593

31 Bai Y, Dou Y, Xie LH, et al. Zr-based metal-organic frameworks: design, synthesis, structure, and applications. Chem Soc Rev, 2016, 45: $2327-2367$

32 Zhang L, Jiang K, Zhang J, et al. Low-cost and high-performance microporous metal-organic framework for separation of acetylene from carbon dioxide. ACS Sustain Chem Eng, 2019, 7: 1667-1672

33 Chang Z, Yang DH, Xu J, et al. Flexible metal-organic frameworks: recent advances and potential applications. Adv Mater, 2015, 27: 5432-5441

34 Wang X, Chi C, Zhang K, et al. Reversed thermo-switchable molecular sieving membranes composed of two-dimensional metalorganic nanosheets for gas separation. Nat Commun, 2017, 8:
14460

35 Rodenas T, Luz I, Prieto G, et al. Metal-organic framework nanosheets in polymer composite materials for gas separation. Nat Mater, 2014, 14: 48-55

36 Matsumoto M, Kitaoka T. Ultraselective gas separation by nanoporous metal-organic frameworks embedded in gas-barrier nanocellulose films. Adv Mater, 2016, 28: 1765-1769

37 Zhang L, Jiang $\mathrm{K}$, Li L, et al. Efficient separation of $\mathrm{C}_{2} \mathrm{H}_{2}$ from $\mathrm{C}_{2} \mathrm{H}_{2} / \mathrm{CO}_{2}$ mixtures in an acid-base resistant metal-organic framework. Chem Commun, 2018, 54: 4846-4849

38 Deng H, Doonan CJ, Furukawa H, et al. Multiple functional groups of varying ratios in metal-organic frameworks. Science, 2010, 327: $846-850$

39 Wen HM, Wang H, Li B, et al. A microporous metal-organic framework with lewis basic nitrogen sites for high $\mathrm{C}_{2} \mathrm{H}_{2}$ storage and significantly enhanced $\mathrm{C}_{2} \mathrm{H}_{2} / \mathrm{CO}_{2}$ separation at ambient conditions. Inorg Chem, 2016, 55: 7214-7218

40 Yang L, Cui X, Zhang Z, et al. An asymmetric anion-pillared metal-organic framework as a multisite adsorbent enables simultaneous removal of propyne and propadiene from propylene. Angew Chem, 2018, 130: 13329-13333

41 Chui SSY, Lo SMF, Charmant JPH, et al. A chemically functionalizable nanoporous material $\left[\mathrm{Cu}_{3}(\mathrm{TMA})_{2}\left(\mathrm{H}_{2} \mathrm{O}\right)_{3}\right]_{n}$. Science, 1999, 283: 1148-1150

42 Kaye SS, Dailly A, Yaghi OM, et al. Impact of preparation and handling on the hydrogen storage properties of $\mathrm{Zn}_{4} \mathrm{O}(1,4$-benzenedicarboxylate) ${ }_{3}$ (MOF-5). J Am Chem Soc, 2007, 129: 1417614177

43 Xue DX, Belmabkhout Y, Shekhah O, et al. Tunable rare earth fcuMOF platform: access to adsorption kinetics driven gas/vapor separations via pore size contraction. J Am Chem Soc, 2015, 137: 5034-5040

44 Yi P, Huang H, Peng Y, et al. A series of europium-based metal organic frameworks with tuned intrinsic luminescence properties and detection capacities. RSC Adv, 2016, 6: 111934-111941

45 Chen F, Wang Y, Bai D, et al. Selective adsorption of $\mathrm{C}_{2} \mathrm{H}_{2}$ and $\mathrm{CO}_{2}$ from $\mathrm{CH}_{4}$ in an isoreticular series of MOFs constructed from unsymmetrical diisophthalate linkers and the effect of alkoxy group functionalization on gas adsorption. J Mater Chem A, 2018, 6: $3471-3478$

46 Zhang L, Jiang K, Li Y, et al. Microporous metal-organic framework with exposed amino functional group for high acetylene storage and excellent $\mathrm{C}_{2} \mathrm{H}_{2} / \mathrm{CO}_{2}$ and $\mathrm{C}_{2} \mathrm{H}_{2} / \mathrm{CH}_{4}$ separations. Cryst Growth Des, 2017, 17: 2319-2322

47 Pang J, Jiang F, Wu M, et al. A porous metal-organic framework with ultrahigh acetylene uptake capacity under ambient conditions. Nat Commun, 2015, 6: 7575

48 Zhang Z, Xiang S, Hong K, et al. Triple framework interpenetration and immobilization of open metal sites within a microporous mixed metal-organic framework for highly selective gas adsorption. Inorg Chem, 2012, 51: 4947-4953

49 Alawisi $\mathrm{H}, \mathrm{Li} \mathrm{B}, \mathrm{He} \mathrm{Y}$, et al. A microporous metal-organic framework constructed from a new tetracarboxylic acid for selective gas separation. Cryst Growth Des, 2014, 14: 2522-2526

50 Chen Z, Xiang S, Arman HD, et al. Three-dimensional pillarlayered copper(II) metal-organic framework with immobilized functional $\mathrm{OH}$ groups on pore surfaces for highly selective $\mathrm{CO}_{2} /$ $\mathrm{CH}_{4}$ and $\mathrm{C}_{2} \mathrm{H}_{2} / \mathrm{CH}_{4}$ gas sorption at room temperature. Inorg Chem, 2011, 50: 3442-3446

51 Cai J, Yu J, Xu H, et al. A doubly interpenetrated metal-organic 
framework with open metal sites and suitable pore sizes for highly selective separation of small hydrocarbons at room temperature. Cryst Growth Des, 2013, 13: 2094-2097

52 Huang $\mathrm{Y}, \mathrm{Lin} \mathrm{Z}, \mathrm{Fu} \mathrm{H}$, et al. Porous anionic indium-organic framework with enhanced gas and vapor adsorption and separation ability. ChemSusChem, 2014, 7: 2647-2653

53 Ma JX, Guo J, Wang H, et al. Microporous lanthanide metalorganic framework constructed from lanthanide metalloligand for selective separation of $\mathrm{C}_{2} \mathrm{H}_{2} / \mathrm{CO}_{2}$ and $\mathrm{C}_{2} \mathrm{H}_{2} / \mathrm{CH}_{4}$ at room temperature. Inorg Chem, 2017, 56: 7145-7150

54 Guo ZJ, Yu J, Zhang YZ, et al. Water-stable In(III)-based metalorganic frameworks with rod-shaped secondary building units: single-crystal to single-crystal transformation and selective sorption of $\mathrm{C}_{2} \mathrm{H}_{2}$ over $\mathrm{CO}_{2}$ and $\mathrm{CH}_{4}$. Inorg Chem, 2017, 56: 2188-2197

55 Chen $\mathrm{Y}, \mathrm{Wu} \mathrm{H}$, Liu $\mathrm{Z}$, et al. Liquid-assisted mechanochemical synthesis of copper based MOF-505 for the separation of $\mathrm{CO}_{2}$ over $\mathrm{CH}_{4}$ or $\mathrm{N}_{2}$. Ind Eng Chem Res, 2018, 57: 703-709

56 Chen $\mathrm{Y}, \mathrm{Wu} \mathrm{H}, \mathrm{Lv} \mathrm{D}$, et al. An ultramicroporous nickel-based metal-organic framework for adsorption separation of $\mathrm{CO}_{2}$ over $\mathrm{N}_{2}$ or $\mathrm{CH}_{4}$. Energy Fuels, 2018, 32: 8676-8682

57 Lu Z, Bai J, Hang C, et al. The utilization of amide groups to expand and functionalize metal-organic frameworks simultaneously. Chem Eur J, 2016, 22: 6277-6285

58 Safarifard V, Rodríguez-Hermida S, Guillerm V, et al. Influence of the amide groups in the $\mathrm{CO}_{2} / \mathrm{N}_{2}$ selectivity of a series of isoreticular, interpenetrated metal-organic frameworks. Cryst Growth Des, 2016, 16: 6016-6023

59 Liu B, Smit B. Molecular simulation studies of separation of $\mathrm{CO}_{2} /$ $\mathrm{N}_{2}, \mathrm{CO}_{2} / \mathrm{CH}_{4}$, and $\mathrm{CH}_{4} / \mathrm{N}_{2}$ by ZIFs. J Phys Chem C, 2010, 114: 8515-8522

60 Liang L, Liu C, Jiang F, et al. Carbon dioxide capture and conversion by an acid-base resistant metal-organic framework. Nat Commun, 2017, 8: 1233

61 Liao PQ, Chen XW, Liu SY, et al. Putting an ultrahigh concentration of amine groups into a metal-organic framework for $\mathrm{CO}_{2}$ capture at low pressures. Chem Sci, 2016, 7: 6528-6533

62 McDonald TM, D'Alessandro DM, Krishna R, et al. Enhanced carbon dioxide capture upon incorporation of $N, N^{\prime}$-dimethyl ethylenediamine in the metal-organic framework CuBTTri. Chem Sci, 2011, 2: 2022-2028

Acknowledgements This work was supported by the National Natural Science Foundation of China (U1609219, 51632008, 61721005, 51432001 and 51772268), and Zhejiang Provincial Natural Science Foundation (LD18E020001).

Author contributions Jiang $\mathrm{K}$ designed and performed the experiments, analyzed the data, and wrote the paper; Zhang L conceived the experiments and contributed to gas sorption measurements; Xia $\mathrm{T}$ synthesized the MOF Eu-BDC- $\mathrm{NH}_{2}$; Yang Y and $\mathrm{Li} \mathrm{B}$ analyzed the data; Cui $Y$ and Qian $G$ conceived the framework of this paper and revised the paper. All authors contributed to the general discussion.

Conflict of interest The authors declare that they have no conflict of interest.

Supplementary information Chemical stability data, thermo stability data and the performance comparison data with other MOF materials are available in the online version of the paper.

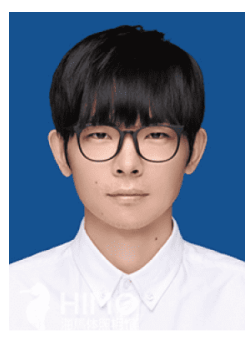

Ke Jiang was born in Shandong, China. He received his double BSc degree at Hainan University and Tianjin University. He is now a $\mathrm{PhD}$ student in Prof. Guodong Qian's laboratory at the School of Materials Science and Engineering, Zhejiang University. His current research focuses on the design and synthesis of metal-organic framework for biomedical application and gas separation.

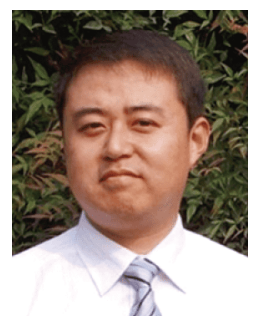

Yuanjing Cui was born in Jiangsu, China. He received his $\mathrm{BSc}$ and $\mathrm{PhD}$ degrees in materials science and engineering from Zhejiang University in 1998 and 2006, respectively. Currently, he is a full professor in the School of Materials Science and Engineering at Zhejiang University. His research interest focuses on organicinorganic hybrid photonic materials.

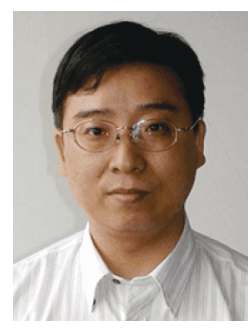

Guodong Qian was born in Zhejiang, China. He received his bachelor's (1988) and master's (1992) degrees in materials science from Zhejiang University in China. He joined the Materials Department of Zhejiang University after obtaining his $\mathrm{PhD}$ degree from Zhejiang University in 1997. He was promoted to associate professor, full professor and Cheung Kong professor in 1999, 2002 and 2011, respectively. His current research interests include hybrid organicmultifunctional porous materials. inorganic photonic functional materials and

\section{具有水稳性且携带氨基官能团的多功能fcu-MOF 用于小分子分离}

\author{
姜珂, 张玲, 夏体锋, 杨雨, 李斌, 崔元靖 ${ }^{*}$, 钱国栋 ${ }^{*}$
}

摘要 甲烷的高效净化对天然气的升级改造具有重要意义. 有效捕 获二氧化碳对缓解温室效应同样具有重要的科研价值. 众所周知, 在材料内部引入一些功能位点, 如开放金属位点、路易斯碱氮位 点、氟基团, 可以显著提高材料对易极化分子的亲和力. 本文中, 我们成功地构建了一种具有水稳性且携带氨基功能基团的铕基金 属有机框架材料. 活化后的样品表现出较强的 $\mathrm{C}_{2}$ 气体吸附, 但对甲 烷的吸附不明显. 其中, 在近室温条件下, 样品对乙炔的吸附量可达 $143.6 \mathrm{~cm}^{3} \mathrm{~cm}^{-3}$, 并且可获得较高的乙炔/甲烷选择性分离系数 (107.7). 此外, 该材料还被证实是一种优异的二氧化碳捕获吸附剂. 在环境条件下, 具有较高的二氧化碳吸附量 $\left(92.6 \mathrm{~cm}^{3} \mathrm{~cm}^{-3}\right)$ 和二氧 化碳/氮气选择性分离系数(151.7). 上述优异的小分子吸附分离性 能主要由收缩孔笼内大量裸露的氨基官能团驱动所致. 这种独特 的效应使该材料呈现优异的甲烷净化和二氧化碳捕获等多功能属 性. 此外, 进一步PXRD分析与水中浸泡后孔隙率的重新测试证实, 该材料具有令人满意的水稳定性. 